\title{
Correction to: Comparison of the effect of activated or non- activated PRP in various concentrations on osteoblast and fibroblast cell line proliferation
}

\author{
Surena Vahabi · Zahra Yadegari · Hossein Mohammad-Rahimi
}

Published online: 21 December 2017

(C) Springer Science+Business Media B.V., part of Springer Nature 2017

Correction to: Cell Tissue Bank (2017) 18:347-353

https://doi.org/10.1007/s10561-017-9640-7

In the original publication of this article, the affiliation of the corresponding author has been published incorrectly. Now the correct affiliation has been provided in this erratum.

The original article can be found online at https://doi.org/10.1007/s10561-017-9640-7.

S. Vahabi $(\square)$

Dental Research Center, Research Institute of Dental

Sciences, Shahid Beheshti University of Medical

Sciences, Tehran, Iran

e-mail: ivsure1@gmail.com

\section{Z. Yadegari}

Departments of Dental Biomaterials, School of Dentistry, Shahid Beheshti University of Medical Sciences, Tehran, Iran

H. Mohammad-Rahimi

Students' Research Committee, School of Dentistry,

Shahid Beheshti University of Medical Sciences, Tehran, Iran 